Canadian Journal of Fisheries and Aquatic Sciences, 1999, v.56, n.S1, Pages 152-161. ISSN: 0706-652X

DOI: $10.1139 /$ cjfas-56-S1-152

http://pubs.nrc-cnrc.gc.ca/rp-ps/journalDetail.jsp?jcode=cjfas\&lang=eng

http://article.pubs.nrc-

cnrc.gc.ca/RPAS/rpv?hm=HInit\&calyLang=eng\&journal=cjfas\&volume=56\&afpf=f99214.pdf

(C) 1999 NRC Canada. 


\title{
Under-ice diel vertical migrations of Oncorhynchus nerka and their zooplankton prey
}

\author{
Geoffrey B. Steinhart and Wayne A. Wurtsbaugh
}

\begin{abstract}
We used stationary hydroacoustics and measures of environmental conditions (water temperature, dissolved oxygen, light levels, and zooplankton) to determine what factors, foraging or predation risk, influenced diel vertical migrations of Oncorhynchus nerka during winter in three high-mountain lakes. The Sawtooth Valley lakes are deep, oligotrophic, glacial lakes located in central Idaho, U.S.A., and historically contained populations of anadromous $O$. nerka. In general, low light intensities limited foraging opportunities of $O$. nerka under ice, especially at night. In Stanley Lake, O. nerka underwent diel vertical migrations to exploit available light to feed. Oncorhynchus nerka occupied shallow water at night, where there was still sufficient light to feed, but were found in deep water during the day. It is unknown whether $O$. nerka occupied deep depths during the day to feed on high densities of zooplankton or to avoid predators. In Alturas Lake, $O$. nerka remained in the top $25 \mathrm{~m}$ both day and night to feed high densities of zooplankton found near the surface. In Redfish Lake, $O$. nerka also showed little migration: $O$. nerka stayed in shallow water both day and night and occupied the same depths with the highest zooplankton densities. The vertical distribution of $O$. nerka during the winter appears to be determined by available food and light, but the deep daytime distribution found in Stanley Lake is still unexplained.
\end{abstract}

\begin{abstract}
Résumé : Les auteurs ont utilisé des senseurs hydroacoustiques stationnaires et mesuré divers paramètres environnementaux (température de l'eau, oxygène dissous, luminosité et zooplancton) pour déterminer quels facteurs, à savoir la quête de nourriture ou le risque de prédation, expliquaient les migrations verticales journalières d'Oncorhynchus nerka en hiver dans trois lacs alpins de la vallée Sawtooth, en Idaho (États-Unis). Ces lacs glaciaires, profonds et oligotrophes, abritent depuis des temps immémoriaux des populations anadromes d'O. nerka. En général, la quête de nourriture était inhibée par la faible luminosité, en particulier la nuit. Dans le lac Stanley, $O$. nerka effectuait des migrations journalières afin d'exploiter la lumière disponible pour se nourrir. Il demeurait en eau peu profonde durant la nuit, y trouvant suffisamment de lumière pour se nourrir, mais regagnait les eaux plus profondes durant la journée. Les auteurs n'ont pas été en mesure de déterminer si $O$. nerka migrait vers les eaux profondes durant le jour pour exploiter les fortes densités de zooplancton ou pour échapper à ses prédateurs. Dans le lac Alturas, $O$. nerka demeurait tant le jour que la nuit dans la couche superficielle formée par les premiers $25 \mathrm{~m}$ d'eau afin de se nourrir des fortes densités de zooplancton observées près de la surface. Dans le lac Redfish, $O$. nerka effectuait des migrations limitées, demeurant en eaux peu profondes tant la nuit que le jour et occupant les strates les plus riches en zooplancton. La distribution verticale de $O$. nerka en hiver semble dictée par la disponibilité de la nourriture et de la lumière. Toutefois, dans le lac Stanley, la présence de $O$. nerka en eaux profondes durant le jour demeure inexpliquée.

[Traduit par la Rédaction]
\end{abstract}

\section{Introduction}

Diel vertical migrations (DVM) are common behavior for many species of aquatic organisms (Cunningham 1972; Levy 1987; Wurtsbaugh and Neverman 1988; Lampert 1989). Among fish, much attention has been focused on the migrations of sockeye (Narver 1970; Eggers 1978; Levy 1990a) and kokanee salmon (Johnston 1990; Levy 1991; Bevelhimer and Adams 1993), both Oncorhynchus nerka. While many researchers have studied diel migratory behav-

Received November 21, 1997. Accepted December 9, 1998. J14317

G.B. Steinhart ${ }^{1}$ and W.A. Wurtsbaugh. Department of Fisheries and Wildlife, and the Ecology Center, Utah State University, Logan, UT 84322-5210, U.S.A.

${ }^{1}$ Author to whom all correspondence should be sent at the following address: Aquatic Ecology Laboratory, The Ohio State University, 227 Research Center, 1314 Kinnear Road, Columbus, OH 43212-1194. U.S.A. ior of $O$. nerka, the explanations for the observed migrations are still under debate.

There are three major hypotheses for the adaptive significance of DVM in fish: foraging, bioenergetics, and predator avoidance (Levy 1987, 1990b; Clark and Levy 1988; Bevelhimer and Adams 1993). The foraging hypothesis predicts that fish will track the movements of their prey, resulting in increased foraging opportunities and higher growth rates (Narver 1970; Levy 1990a, 1990b). Bioenergetics hypotheses predict that fish will select temperatures that either increase digestion rates (Wurtsbaugh and Neverman 1988; Neverman and Wurtsbaugh 1994) or maximize net growth efficiency (Brett 1971; Brett and Groves 1979), both resulting in higher growth rates (Bevelhimer and Adams 1993). Predator avoidance theory states that by minimizing exposure to predators, fish will increase survival, even though growth may be depressed (Levy 1987, 1990b; Clark and Levy 1988).

It is likely that the migratory behaviors of many $O$. nerka populations are a combination of these factors; for example, 
Table 1. Physical and biological characteristics of the Sawtooth Valley lakes during ice cover from December 1993 to March 1995.

\begin{tabular}{lllll}
\hline Lake & Surface area $\left(\mathrm{km}^{2}\right)$ & Maximum depth $(\mathrm{m})$ & Mean chlorophyll $a\left(\mathrm{mg} / \mathrm{m}^{3}\right)$ & Mean zooplankton biomass $(\mu \mathrm{g} / \mathrm{L})$ \\
\hline Redfish & 6.17 & 91 & 0.58 & 1.8 \\
Alturas & 3.38 & 53 & 0.74 & 3.5 \\
Stanley & 0.73 & 26 & 0.96 & 6.1 \\
& &
\end{tabular}

Note: Chlorophyll $a$ values are from surface samples $(0-6 \mathrm{~m})$. Zooplankton biomass is a whole-lake average of crustacean zooplankton except nauplii.

Table 2. Gillnet catch-per-net-hour (CPUE) for piscivorous fish in the Sawtooth Valley lakes.

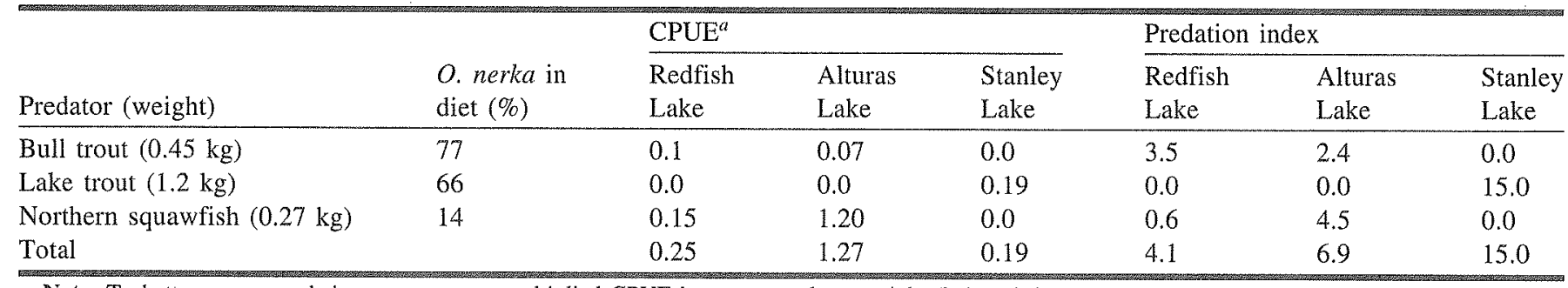

Note: To better assess predation pressure, we multiplied CPUE by mean predator weight $(\mathrm{kg})$ and the percentage of $O$. nerka in the predator's diet to create a predation index.

${ }^{a}$ Data from Spaulding (1993), Kline (1994), and Teuscher and Taki (1994).

the growth to mortality ratio or the foraging to survival ratio (Levy 1987, 1990a, 1990b; Bevelhimer and Adams 1993). It is difficult, however, to determine which factors are most important in determining migration patterns because of confounding elements in many studies. For example, most studies have been done when lakes are thermally stratified, so it has been difficult to distinguish between bioenergetic advantages and the effects of prey and predators on the diel vertical distributions of fish (Beauchamp et al. 1997).

Here, we describe the patterns of DVM during winter for $O$. nerka in three high-mountain, oligotrophic lakes. The results of this study allow closer examination of the current hypotheses on what drives $O$. nerka vertical migrations. Nearly constant temperature profiles during winter eliminate possible physiological benefits of migration, while different predator densities between lakes demonstrate the influence of the predator avoidance hypothesis. Winter zooplankton abundance in these lakes can be extremely low, and $O$. nerka may have trouble meeting their maintenance ration (Teuscher and Taki 1995; Steinhart 1997), so we hypothesized that the foraging hypothesis played a major role in structuring the vertical distribution of $O$. nerka. In addition, we examined how low light penetration may limit feeding and influence the observed patterns of DVM for visually foraging $O$. nerka. Finally, describing DVM patterns of $O$. nerka in winter will better our understanding of how $O$. nerka populations use available resources and what might limit their populations in winter.

\section{Methods}

\section{Study site}

Redfish, Stanley, and Alturas lakes are glacially formed, highaltitude lakes $(1985-2138 \mathrm{~m})$ located in the Sawtooth Valley of central Idaho, U.S.A. $\left(44^{\circ} \mathrm{N}, 115^{\circ} \mathrm{W}\right)$. In general, all three lakes are oligotrophic, with little macrophyte growth, low chlorophyll levels, and low zooplankton biomass, but differ in size and depth (Table 1). The Sawtooth Valley lakes are typically ice covered for at least 5 months each year, and during this study, snow and ice thickness varied from 30 to $75 \mathrm{~cm}$.
All three lakes contain kokanee, a type of sockeye salmon that do not migrate to the ocean as adults, but only Redfish Lake is known to contain both kokanee and sockeye salmon. As juveniles, the two types are functionally similar (from here on, we will refer to sockeye and kokanee collectively as $O$. nerka). Data from summer and fall nearshore gillnet studies and winter under-ice gillnet surveys (for methods, see Spaulding 1993; Kline 1994; Teuscher and Taki 1994) were used to estimate predator abundance and diet to calculate relative indices of predation risk for the lakes (Table 2). Stanley Lake appeared to have the highest predation risk due to a large population of predaceous lake trout (Salvelinus namaycush). Redfish Lake contains some piscivorous bull trout (Salvelinus confluentus) and northern squawfish (Ptychocheilus oregonensis). Alturas Lake has a low density of bull trout but a large population of northern squawfish. Other fish species present in the lakes include rainbow trout (Oncorhynchus mykiss), brook trout (Salvelinus fontinalis), suckers (Catastomus spp.), redside shiner (Richardsonius balteatus), dace (Rhinichthys spp.), and sculpin (Cottus spp.). Rainbow trout found in these lakes are hatcherystocked fish, and few survive overwinter, and while both the rainbow and brook trout eat juvenile salmon, no salmon were found in their diets during the course of this study (Teuscher and Taki 1995).

\section{Data collection}

On each sampling date, samples were collected near the deepest section of each lake. A hole was cut through the ice using either an ice auger or a chainsaw. The depths of snow and of the different ice layers were recorded, as was light intensity. Temperature and dissolved oxygen profiles were measured using a YSI model 58 dissolved oxygen meter. For a complete description of limnological methods, see Budy et al. (1995).

Light intensity was measured using a submersible Li-Cor model LI-188B radiometer through a hole about $0.75 \mathrm{~m}^{2}$ cut by chainsaw. The spherical light sensor measured light between 400 and $700 \mathrm{~nm}$. To avoid increased light intensity surrounding the hole, the sensor was extended about $3 \mathrm{~m}$ away from the hole using a plastic pipe equipped with floatation to keep the pipe near the surface. A metered cable and line were passed through the plastic pipe and attached to a weighted and self-righting arm that held the sensor (Fig. 1). Snow and ice were piled back into the hole to reduce light penetration from the hole. The probe was slowly lowered at $1-\mathrm{m}$ intervals to $36 \mathrm{~m}$, or until light was undetectable $\left(<0.1 \mu\right.$ einsteins $\left.\cdot \mathrm{m}^{-2} \cdot \mathrm{s}^{-1}\right)$. During the sampling period, a deck cell 
Fig. 1. Diagram of gear deployment during periods of ice cover on the Sawtooth Valley lakes. Holes were cut using either an auger or a chainsaw. Hydroacoustics and gill nets were used to measure the vertical distributions of fish. Note the construction of the flexible plastic pole used to extend the underwater light sensor away from the light surrounding the hole, but keeping the sensor near the surface of the ice.

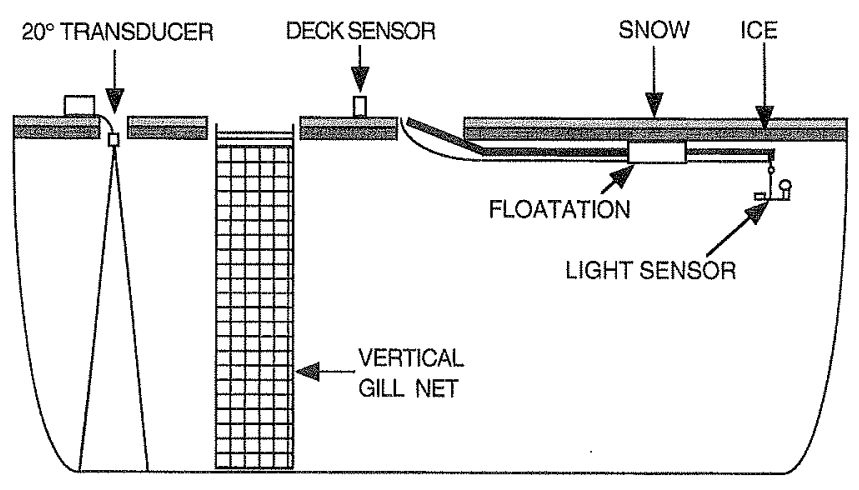

measuring incident light intensities was used to correct for changes in light intensity from clouds passing overhead.

To examine the extent of light-limited foraging, under-ice light intensities for a diel period were calculated using the percent light blocked by ice and snow, extinction coefficients, and a computer program that predicts surface intensity based on location, percent cloud cover (estimated during field sampling), and sunlight and moonlight (Janiczek and Young 1987). The percent light blocked by ice and snow was calculated for each sample date by dividing the light intensity immediately beneath the ice by the light intensity measured just below the surface of the water in the open hole. We calculated extinction coefficients as the slope of the regression of the natural log of percent surface intensity against depth (Wetzel and Likens 1991). Light intensities measured in einsteins were converted to units of lux or foot-candles for consistency with available literature on sockeye feeding $\left(1 \mathrm{~lx} \cong 1.95 \times 10^{-2} \mu\right.$ einsteins $/ \mathrm{m}^{2}-\mathrm{s} \cong$ $0.093 \mathrm{ft}$-candle).

Zooplankton samples were collected using a closing conical net $35 \mathrm{~cm}$ in diameter and $80 \mathrm{~cm}$ long with $80-\mu \mathrm{m}$ mesh. The net was equipped with a flowmeter to calculate net efficiencies. In each lake, zooplankton samples were collected at two stations separated by at least $50 \mathrm{~m}$ and over several discrete depth strata, depending on sample protocol (diel or routine sampling) and the lake. Diel zooplankton sampling in Stanley Lake occurred between 12:15 and 12:45 and between 00:00 and 00:30 on 17-18 March 1995 (strata: $0-2,2-5,5-10$, and $10-17 \mathrm{~m}$ and $17 \mathrm{~m}$ to the bottom). Diel zooplankton sampling in Redfish Lake was from 12:00 to 13:30 and from 00:00 to 01:30 on 22-23 January 1995 (strata: 0-2, 2-5, 5$10,10-20,20-40$, and $60 \mathrm{~m}$ to the bottom). Daytime-only depthstratified samples were collected in Alturas Lake on 23 February 1995 (strata: $0-10$ and $10-20 \mathrm{~m}$ and $20 \mathrm{~m}$ to the bottom) and in Stanley Lake on 22 March 1994 (strata: $0-10 \mathrm{~m}$ and $10 \mathrm{~m}$ to the bottom). Zooplankton samples were preserved in $10 \%$ neutralized formalin solution and were enumerated and measured in the laboratory. Dry biomass was calculated by length-weight regressions from McCauley (1984) and Koenings et al. (1987). Copepod nauplii are not included in the zooplankton data reported here, as nauplii rarely appeared in $O$. nerka diets.

A two-way repeated measures analysis of variance (ANOVA) was used to test for DVM for all zooplankton combined and by individual species. For all zooplankton, time and depth were factors and zooplankton biomass (micrograms per litre) was the independent variable. For individual taxa, the independent variable was the percentage of the total taxa population in each stratum (arcsine transformed; Sokal and Rohlf 1981). Since the abundance of some taxa was low, and was variable between night and day, percentages were used to avoid any confounding results due to different catch rates at different times. A significant interaction between time and depth indicated that the two distributions were not similar and a diel migration did occur.

Hydroacoustic sampling of fish distributions was conducted concurrently with the limnological and zooplankton diel sampling using a Lowrance X-16 chart recorder. Data on fish distributions were collected for a 24 -h period using a stationary transducer deployed through the ice. The downward-facing transducer $\left(20^{\circ}\right.$ beam angle, $200 \mathrm{kHz}$ ) was placed at the bottom edge of the ice through an auger-cut hole (Fig. 1). The hole was subsequently filled with snow to prevent excess light penetration. The gain was adjusted to the maximum setting that did not result in noise levels that would prevent detection of fish in the top $5 \mathrm{~m}$.

The time and depth of each fish target on the chart paper were recorded. To determine the time of occurrence for each target, the distance from the start of the roll was measured and converted to minutes elapsed using a regression between distance and time. Only targets deeper than $2 \mathrm{~m}$ were recorded because the transducer was not able to discern targets closer than $2 \mathrm{~m}$. To separate daytime and nighttime targets, data from $1 \mathrm{~h}$ before until $1 \mathrm{~h}$ after sunrise and sunset are excluded from the analyses. The data were corrected for transducer beam spread by calculating the density of targets in each depth stratum based on the volume sampled. We did not correct for small $O$. nerka near the edge of the beam, or far away from the transducer, that may not have been detected due to spreading losses. However, summer acoustic surveys collected with a scientific-grade echosounder suggest that $O$. nerka were typically found shallower than $30 \mathrm{~m}$ (Teuscher and Taki 1994; Beauchamp et al. 1997), so we do not think that this shortcoming would affect our results. Since there was no replication of the acoustic data, we used a $\chi^{2}$ test to test for differences between day and night vertical distributions of $O$. nerka. In addition, each distribution (day and night) was compared with a random distribution of fish using a $\chi^{2}$ test.

Vertical gill nets were used to provide target identification to supplement the hydroacoustic sampling. Three vertical gill nets ( $3 \mathrm{~m}$ wide by $25 \mathrm{~m}$ deep, $19-, 25-$, and $38-\mathrm{mm}^{2}$ square mesh) were marked in $2.5-\mathrm{m}$ increments and were set so that they stretched from the surface to the bottom in Stanley Lake and from the surface to $25 \mathrm{~m}$ in Alturas Lake. Preliminary sampling indicated that nets did not capture fish during the day, so they were only checked in the morning, between 08:00 and 10:00. We assumed that all fish in the nets were captured between dusk and dawn. Redfish Lake was not sampled with gill nets because it contains endangered sockeye salmon. In Alturas Lake, two bull trout were captured by vertical gill nets set under the ice, but in general, under-ice gillnetting was ineffective ( 100 . nerka captured in 225 net-hours). For these lakes, we used previous data from midwater trawls (summer 1993, 1994, and 1995, November 1993 and 1994, and May 1994 and 1995) that showed that $O$. nerka make up nearly $100 \%$ of the pelagic fish population (where our acoustic sampling occurred). Previous gillnet surveys have found that predators were typically found in littoral and benthic areas (Kline 1994; Steinhart 1997).

To test the hypothesis that $O$. nerka migrate to maximize food intake (a combination of both prey density and foraging ability), a simple model of feeding rates was created. Instantaneous clearance rates at different light intensities were calculated using the equation from Dodson (1975):

$$
k=-\log _{\mathrm{e}} \frac{\left(P_{f} / P_{i}\right)}{X t}
$$

where $k$ is clearance rate (litres per hour), $P_{\mathrm{f}}$ is the final number of prey in the tank, $P_{\mathrm{i}}$ is the initial number of prey, $X$ is the number of 
Fig. 2. Thickness of snow, slush, and ice and the depth of $1 \%$ surface light intensity (compensation point) for (A) Stanley,

(B) Redfish, and (C) Alturas lakes during 1993-1995.

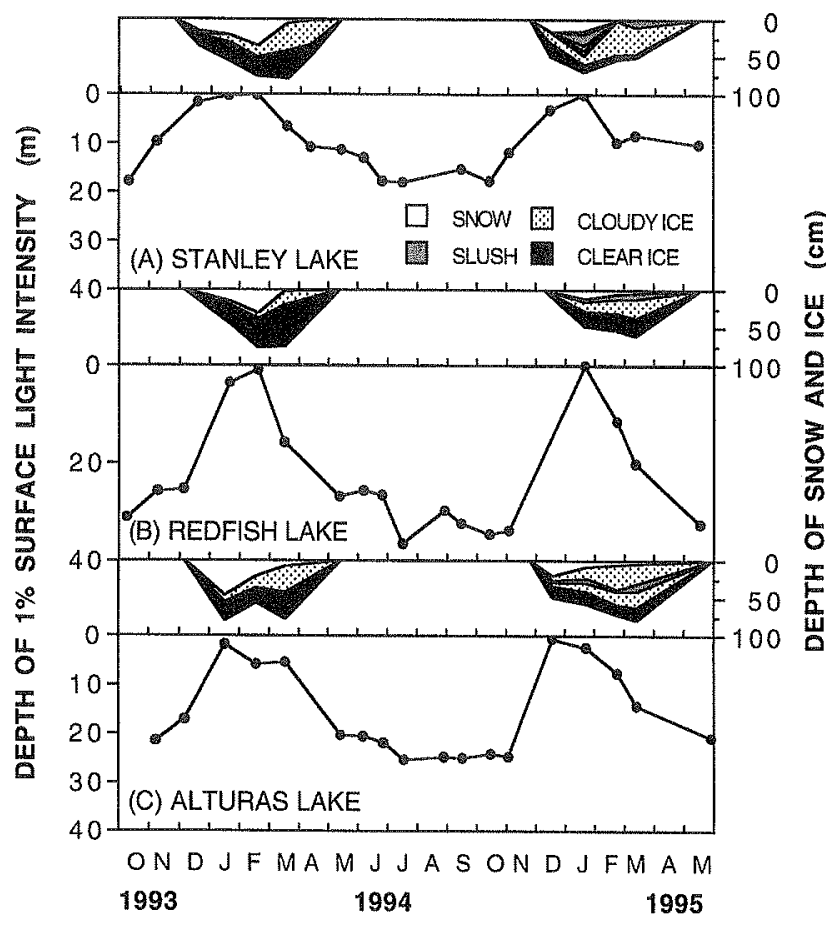

predators in the tank, and $t$ is time (hours). Data from Ali's (1959) work on $O$. nerka capture success in laboratory experiments were used to calculate $k$ at different light intensities. We multiplied our estimate of clearance rate $(k)$ by the ambient zooplankton density to calculate the maximum consumption of zooplankton by $O$. nerka at observed light intensities. Three different DVM strategies were tested using this model: (i) remain shallow throughout the day and night, (ii) remain deep, and (iii) remain deep during the day and shallow at night.

\section{Results}

Under-ice light intensities varied among the lakes. Stanley Lake had the lowest mean light penetration (Fig. 2A) because it froze over earlier in the year, was covered by thick ice, and its small fetch resulted in more snow accumulation. Light penetration was often highest in Redfish and Alturas lakes (Figs. 2B and 2C). Since these lakes are deeper than Stanley Lake, a larger proportion of the water column was not sufficiently illuminated for foraging.

Winter zooplankton abundance and species composition differed among lakes but were generally dominated by Bosmina longirostris, Daphnia rosea, and an unidentified cyclopoid copepod. In general, there was little DVM of zooplankton under ice during this study. For Stanley Lake, in March 1995, zooplankton biomass was $<3 \mu \mathrm{g} / \mathrm{L}$ in most of the water column, with a higher biomass $(>6 \mu \mathrm{g} / \mathrm{L})$ found near the bottom of the lake (Fig. 3A). As a whole, there was no DVM of the zooplankton; however, Bosmina sp. showed a slight migration toward the surface at night (Table 3 ). Nearly all cyclopoids were located between 17 and $24 \mathrm{~m}$ throughout the sampling period. During March 1994, the daytime zooplankton abundance was extremely low
Fig. 3. Diel vertical distribution of (A) crustacean zooplankton (not including copepod nauplii) $( \pm 1 \mathrm{SE})$ and (B) O. nerka in Stanley Lake on 17 March 1995. Also shown are temperature (solid line), dissolved oxygen (broken line), predicted $O$. nerka depths of foraging success (arrows and \% success), and the number of targets from the hydroacoustic data $(N)$.

\section{ZOOPLANKTON BIOMASS $(\mu \mathrm{g} / \mathrm{L})$}

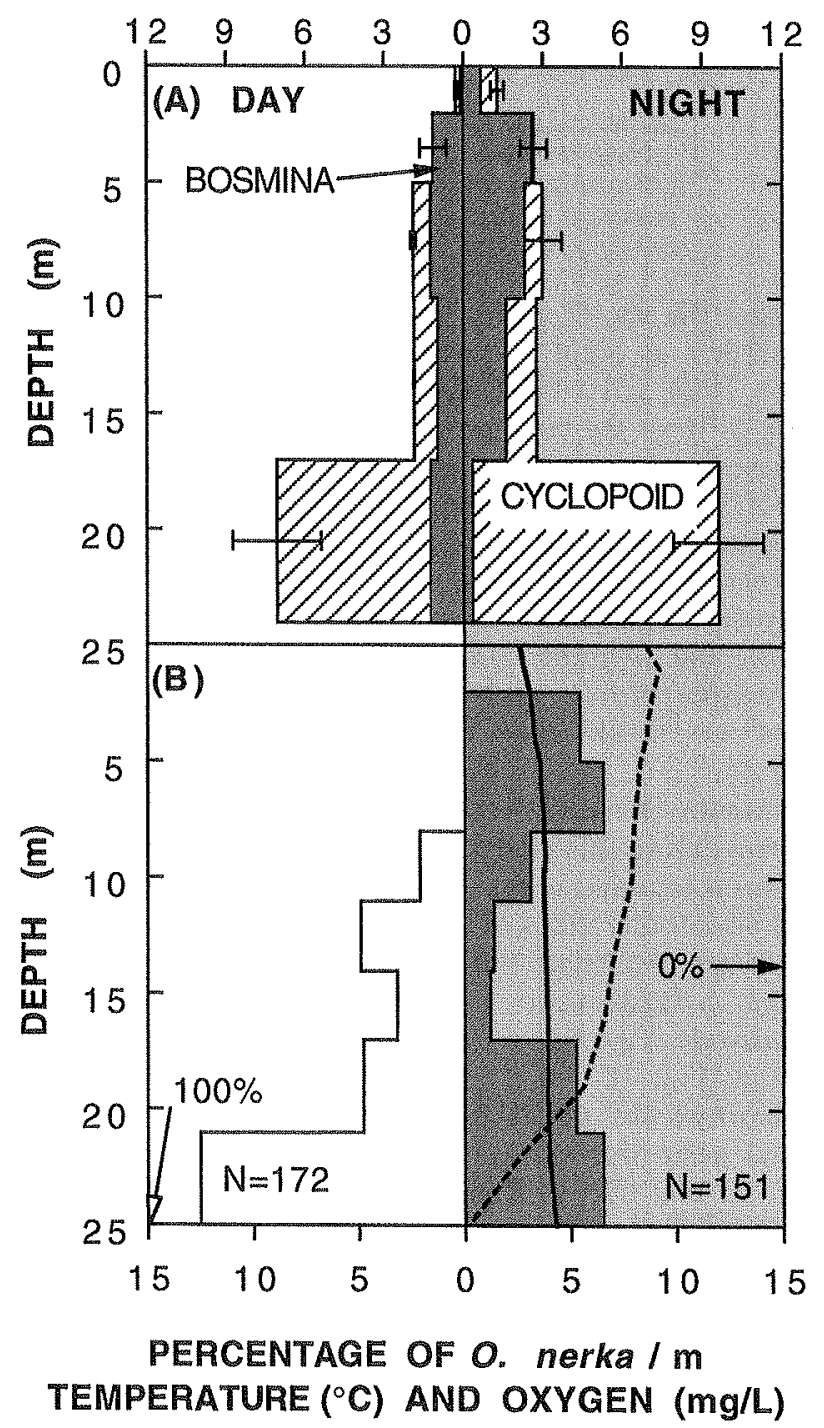

$(0.6 \mu \mathrm{g} / \mathrm{L})$ in Stanley Lake (Fig. 4A). For Redfish Lake, the highest biomass of zooplankton was in the 0 - to $2-\mathrm{m}$ stratum $(>1 \mu \mathrm{g} / \mathrm{L})$ (Fig. 5A), but the mean biomass was only $0.4 \mu \mathrm{g} / \mathrm{L}$. Overall, DVM by all zooplankton in Redfish Lake was insignificant; however, Bosmina sp. showed a significant upward migration at night (Table 3). Zooplankton densities in Alturas Lake were low $(0.7 \mu \mathrm{g} / \mathrm{L})$ throughout the water column, but biomass was higher near the surface than below $10 \mathrm{~m}$ (Fig. 6A). We assumed that this daytime sample was representative of the nighttime distribution because diel sampling of the zooplankton distribution in Alturas Lake was conducted in February 1994 and found no significant diel migration of plankton (G.B. Steinhart, unpublished data). 
Table 3. Results of ANOVA of zooplankton DVM in Stanley and Redfish lakes.

\begin{tabular}{lllll} 
& & ANOVA $p$ values & & \\
\cline { 3 - 5 } Lake & Zooplankton & Depth & Time & Depth $\times$ time \\
\hline Stanley, 17 Mar. 1995 & All & 0.007 & 0.003 & 0.59 \\
& Bosmina & 0.03 & 0.29 & 0.03 \\
& Cyclopoid copepods & $<0.0001$ & 0.93 & 0.10 \\
Redfish, 22 Jan. 1995 & All & 0.001 & 0.37 & 0.08 \\
& Bosmina & $<0.0001$ & 0.16 & 0.04 \\
& Daphnia & $<0.0001$ & 0.60 & 0.40 \\
& Cyclopoid copepods & 0.0002 & 0.70 & 0.94
\end{tabular}

\footnotetext{
Note: We tested the migration of the total crustacean zooplankton population by comparing total zooplankton density at different depths and times. Migrations of each zooplankton group were analyzed by comparing the arcsine-transformed percentage of individuals per metre at different depths and times. A significant depth $\times$ time interaction indicates that the day and night distributions were different.
}

Under the ice, $O$. nerka in Stanley Lake migrated toward the surface at night but remained deep during the day in March 1994 and 1995 (Figs. 3B and 4B). In March 1995, nearly $50 \%$ of the targets were detected below $21 \mathrm{~m}$ during the day; however, at night, $<20 \%$ were deeper than $21 \mathrm{~m}$ and over $30 \%$ of the targets were shallower than $8 \mathrm{~m}$ (Fig. 3B). The distribution of $O$. nerka during the day was significantly different than at night, and both distributions were significantly different from random (Table 4). On 22 March 1994, daytime and nighttime distributions of $O$. nerka were significantly different from each other, but only the daytime distribution was significantly different from random (Fig. 4B; Table 4).

In Stanley Lake, only $O$. nerka were captured in vertical gill nets during this study, and only $O$. nerk $a$ and lake trout have been captured in previous studies (some lake trout were captured in other areas of the lake and on other winter sampling dates (Steinhart 1997)). We therefore assume that all of the hydroacoustic targets were $O$. nerka salmon. Oncorhynchus nerka were captured at depths ranging from 7 to $19 \mathrm{~m}$ (Fig. 7).

Oncorhynchus nerka in Redfish and Alturas lakes remained near the surface throughout the day and night (Figs. 5B and 6B). In Redfish Lake, O. nerka did not show any significant change in vertical distribution from day to night (Table 4). The distribution was highly skewed, with all the targets detected above $20 \mathrm{~m}$ and the highest proportion of fish in the 2- to 5-m stratum (Fig. 5B). Both these distributions were significantly different from random (Table 4). Oncorhynchus nerka in Alturas Lake had a significant upwards vertical migration at night (Table 4), but the magnitude of this migration was small: $O$. nerka were concentrated closer to the surface at night, but during day and night, few $O$. nerka were detected below $14 \mathrm{~m}$ (Fig. 6B). In general, fewer $O$. nerka were detected in Redfish and Alturas lakes than in Stanley Lake in March 1995.

The greatest $O$. nerka capture rates of zooplankton were usually shallow $(<30 \mathrm{~m})$ in the lakes, due to the decreased light penetration (Fig. 8). This was especially evident in Redfish and Alturas lakes, where zooplankton density varied little with depth, and changes in capture rates reflected changes in light levels. In Redfish Lake, consumption was highest near the surface during the day, with a small peak around 20-30 m due to a slight increase in zooplankton density. Relatively high light penetration into Alturas Lake resulted in the highest predation rates in the top $35 \mathrm{~m}$ during the day, but there was little or no feeding at night. In 1995 in Stanley Lake, the high zooplankton abundance near the bottom resulted in a huge increase in capture rates. However, in 1994 and during the night in 1995, capture rates were highest in the illuminated surface waters. Low light intensities and little light penetration through the snow and ice limited nighttime feeding opportunities in all three lakes.

The results of our feeding rate model for Stanley Lake demonstrate the importance of light for maximizing food intake. Oncorhynchus nerka that migrated toward the surface at night could increase their consumption by at least $12 \%$ over nonmigrating fish (Table 5). This increase in consumption was caused by higher clearance rates in the illuminated surface waters than at the dark bottom at night. These results are especially important at low zooplankton densities but may not be important when food is more abundant.

\section{Discussion}

Oncorhynchus nerka in the Sawtooth Valley lakes migrated on a diel cycle under the ice on some occasions. The ecological significance of these migrations appeared to be a combination of foraging success and possibly predator avoidance. Spatially variable prey abundance and limited foraging ability due to low light intensities limited the feeding opportunities for $O$. nerka. As a result, the salmon migrated to make use of available light and to exploit areas of highest zooplankton abundance. Predator avoidance may have played a role in structuring the migrations in Stanley Lake. Physiological benefits due to differences in temperature should not have been a factor during winter in any of these lakes.

The foraging hypothesis predicts that $O$. nerka will migrate to depths where food is more abundant, or where feeding is more efficient. Due to low light intensities under the ice, it was common for only the surface portion of the water column to be available for visual prey detection by $O$. nerka. Consequently, fish would have been near the surface to see and, therefore, to feed. In Stanley Lake, O. nerka feeding was not inhibited by light levels during the day; however, at night, only the surface waters were available for visual feeding. Even though higher zooplankton densities were present at the bottom of the lake, O. nerka in Stanley Lake migrated up at night to depths where there was sufficient light to permit foraging. In Redfish and Alturas lakes, $O$. nerka remained in the surface waters where light levels and zoo- 
Fig. 4. (A) Noon vertical distribution of crustacean zooplankton (not including copepod nauplii) $( \pm 1 \mathrm{SE})$ and $(\mathrm{B})$ diel vertical distribution of O. nerka in Stanley Lake on 22 March 1994. BOS, Bosmina; CYC, cyclopoid copepods. Also shown are temperature (solid line), dissolved oxygen (broken line), predicted $O$. nerka depths of foraging success (arrows and \% success), and the number of targets from the hydroacoustic data $(N)$.

\section{ZOOPLANKTON BIOMASS ( $\mu \mathrm{g} / \mathrm{L})$}

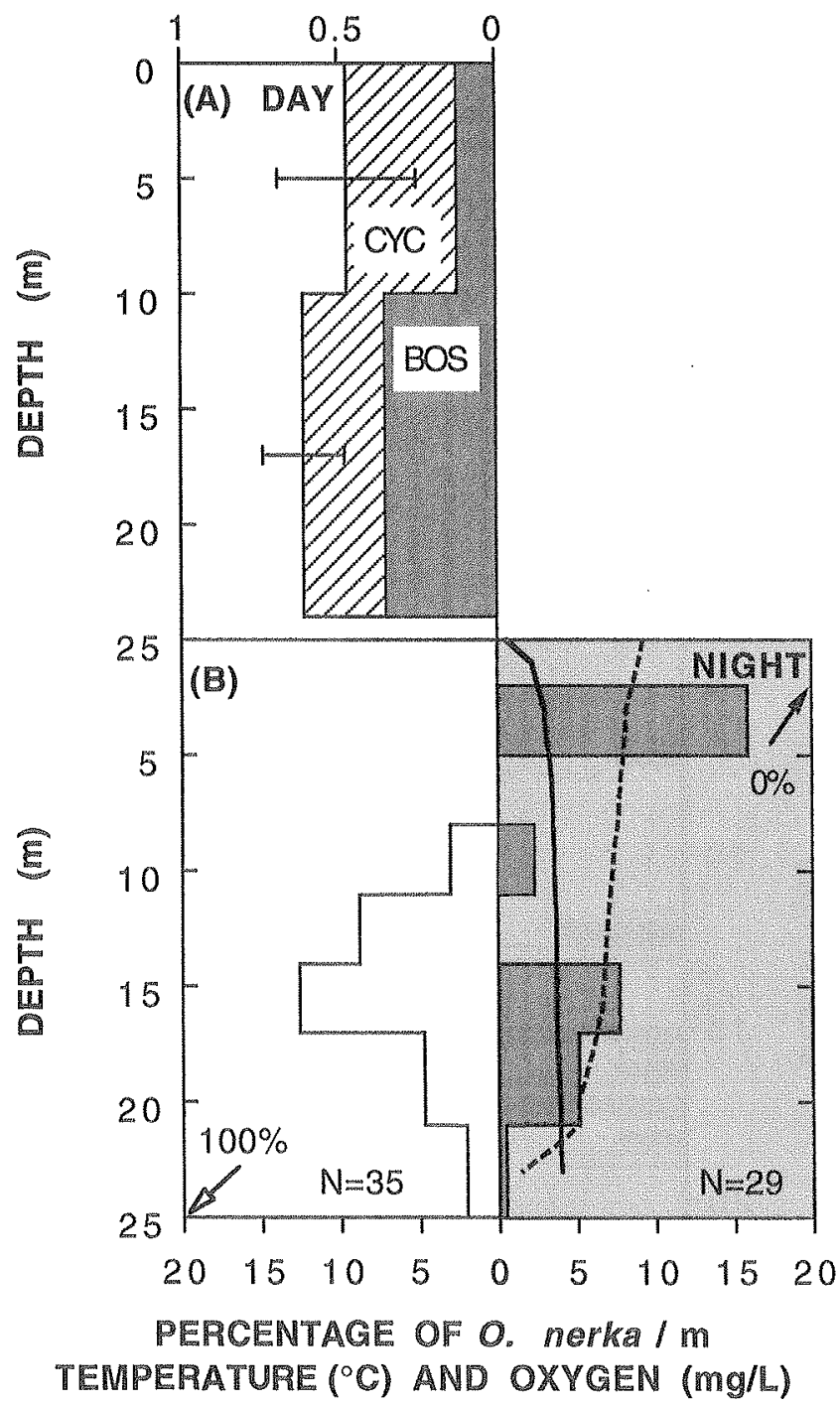

plankton density and biomass were highest. This suggests that $O$. nerka inhabit waters where they can capture the most prey, a combination of prey density and foraging success, and not necessarily where prey numbers are highest.

Low light intensities may have prevented $O$. nerka from meeting their metabolic demands during the winter. Even with DVM, $O$. nerka consumption in Stanley Lake was extremely low, necessitating nearly continual feeding to maintain growth. At $4^{\circ} \mathrm{C}$, juvenile sockeye need to consume about $0.4 \%$ of their dry weight per day to sustain positive growth (Brett 1983). Consumption by vertically migrating $O$. nerka would be $0.095 \%$ of dry weight per day in March 1994 and 1.25\% per day in March 1995. To meet basic metabolic costs, $O$. nerka may have migrated into higher con-
Fig. 5. Diel vertical distribution of (A) crustacean zooplankton (not including copepod nauplii) $( \pm 1 \mathrm{SE}$ ) and (B) O. nerka in Redfish Lake on 22 January 1995. Also shown are temperature (solid line), dissolved oxygen (broken line), predicted $O$. nerka depths of foraging success (arrows and \% success), and the number of targets from the hydroacoustic data $(N)$.

ZOOPLANKTON BIOMASS ( $\mathrm{g} / \mathrm{L} / \mathrm{L})$

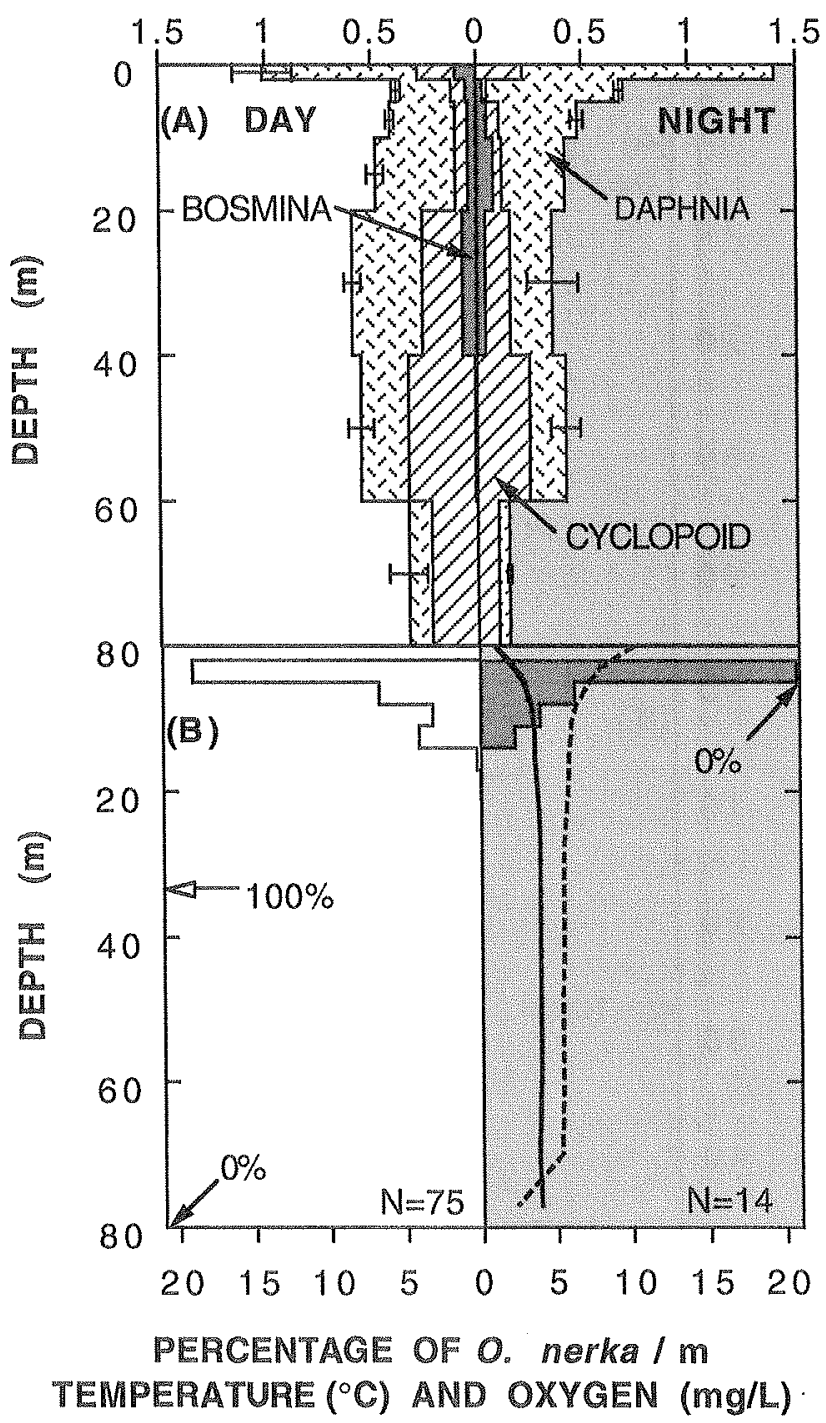

centrations of prey to feed. Although low dissolved oxygen levels were found deep in Stanley Lake ( $<4 \mathrm{mg} / \mathrm{L}$ ) (Figs. 3B and $4 \mathrm{~B}$ ), many acoustic targets were detected below $21 \mathrm{~m}$, suggesting that $O$. nerka tolerated the low oxygen levels, possibly in order to feed on the high abundance of zooplankton near the bottom.

Light levels were sufficient to allow foraging in the top $10-20 \mathrm{~m}$ in Stanley Lake during this study, but on other dates, light-limited feeding may be more important. Our sampling took place on cloudless nights with nearly a full moon (in 1995) or a partial moon (in 1994): on moonless or cloudy nights, $O$. nerka feeding may be more limited than under the conditions we sampled. Indeed, O. nerka in Stanley and Alturas lakes lost lipid over the winter and may have experienced mortality of smaller size-classes (Steinhart 
Fig. 6. (A) Noon vertical distribution of crustacean zooplankton (not including copepod nauplii) ( $\pm 1 \mathrm{SE}$ ) and (B) diel vertical distribution of $O$. nerka in Alturas Lake on 23 February 1995. Also shown are temperature (solid line), dissolved oxygen (broken line), predicted $O$. nerka depths of foraging success (arrows and \% success), and the number of targets from the hydroacoustic data $(N)$.

\section{ZOOPLANKTON BIOMASS ( $\mu \mathrm{g} / \mathrm{L})$}

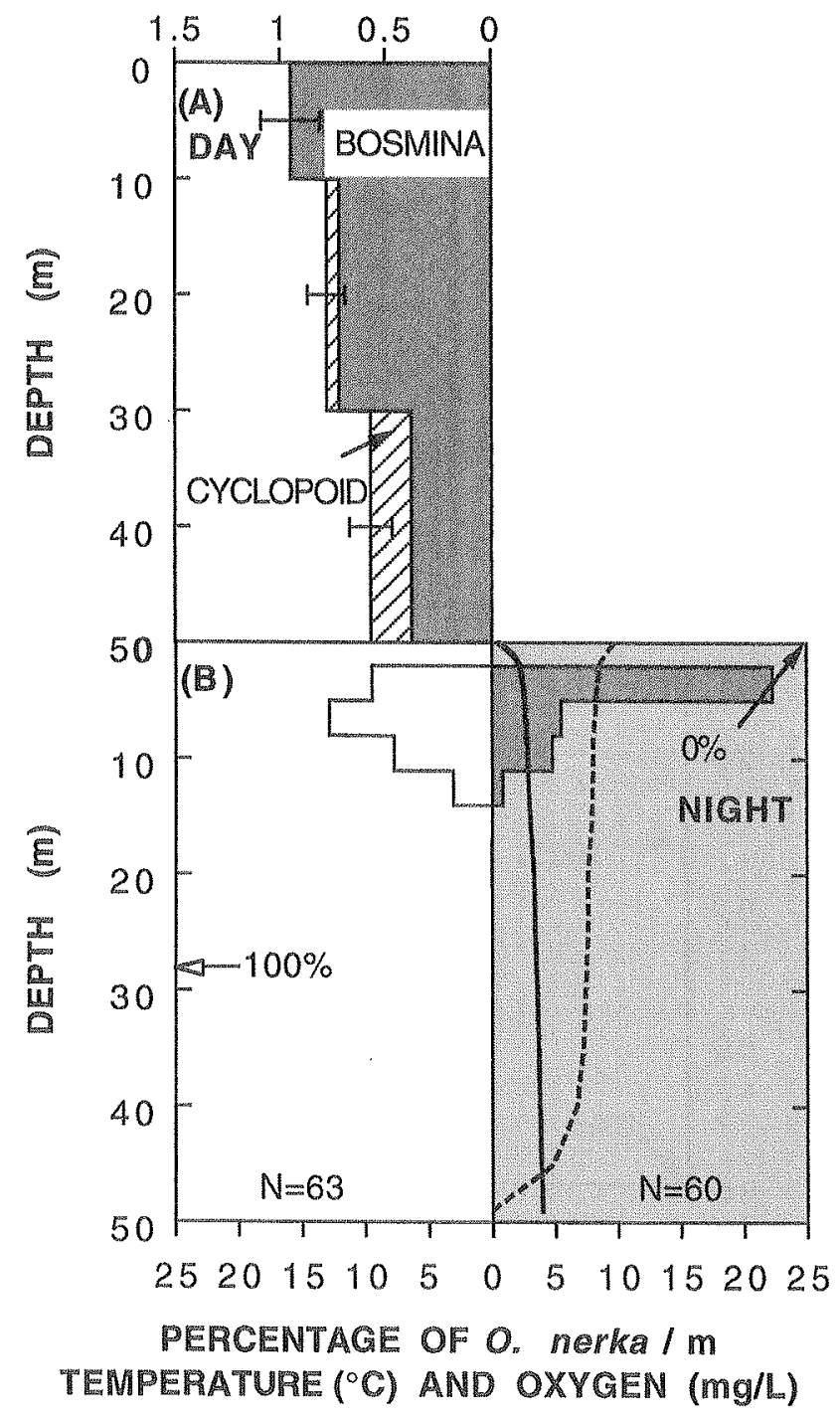

1997). Furthermore, in Alturas Lake, benthic zooplankton and insects such as Alona spp. and chironomid larvae were found in the diets of $O$. nerka, suggesting that $O$. nerka may move to nearshore slopes or benthic areas to look for alternative prey when foraging is limited by low light or low zooplankton densities.

Oncorhynchus nerka depth distribution from the gill nets and hydroacoustics were similar in Stanley Lake, but we may have missed a portion of the $O$. nerka population that moved into benthic or nearshore areas. Furthermore, in the deeper Redfish and Alturas lakes, we may have failed to detect some deep $(>30 \mathrm{~m})$ targets. The Lowrance X-16 does not have a time-varied gain, so deep targets in these lakes may not have been detected due to attenuation of the acous-
Table 4. Results of $\chi^{2}$ tests of $O$. nerka vertical distributions.

\begin{tabular}{lllll} 
& & \multicolumn{2}{c}{$\chi^{2}$ test $p$ values } \\
\cline { 4 - 5 } Lake & Date & Time & Night & Random \\
\hline Stanley & 22 Mar. 1994 & Day & $<0.001$ & $<0.001$ \\
& & Night & na & $<0.001$ \\
Stanley & 18 Mar. 1995 & Day & $<0.001$ & $<0.001$ \\
& & Night & na & 0.23 \\
Redfish & 22 Jan. 1995 & Day & 0.99 & $<0.001$ \\
& & Night & na & $<0.001$ \\
Alturas & 23 Feb. 1995 & Day & $<0.001$ & $<0.001$ \\
& & Night & na & $<0.001$ \\
& & & &
\end{tabular}

Note: A significant $p$ value represents a significant difference between day and night distributions of $O$. nerka or a difference of day or night vertical distribution from a random distribution (i.e., evenly distributed population).

Fig. 7. Vertical distribution of $O$. nerka captured in vertical gill nets in Stanley Lake during March 1994 and March 1995.

Preliminary work showed that no fish were captured during the day, so it was assumed that all fish were caught during night or crepuscular periods.

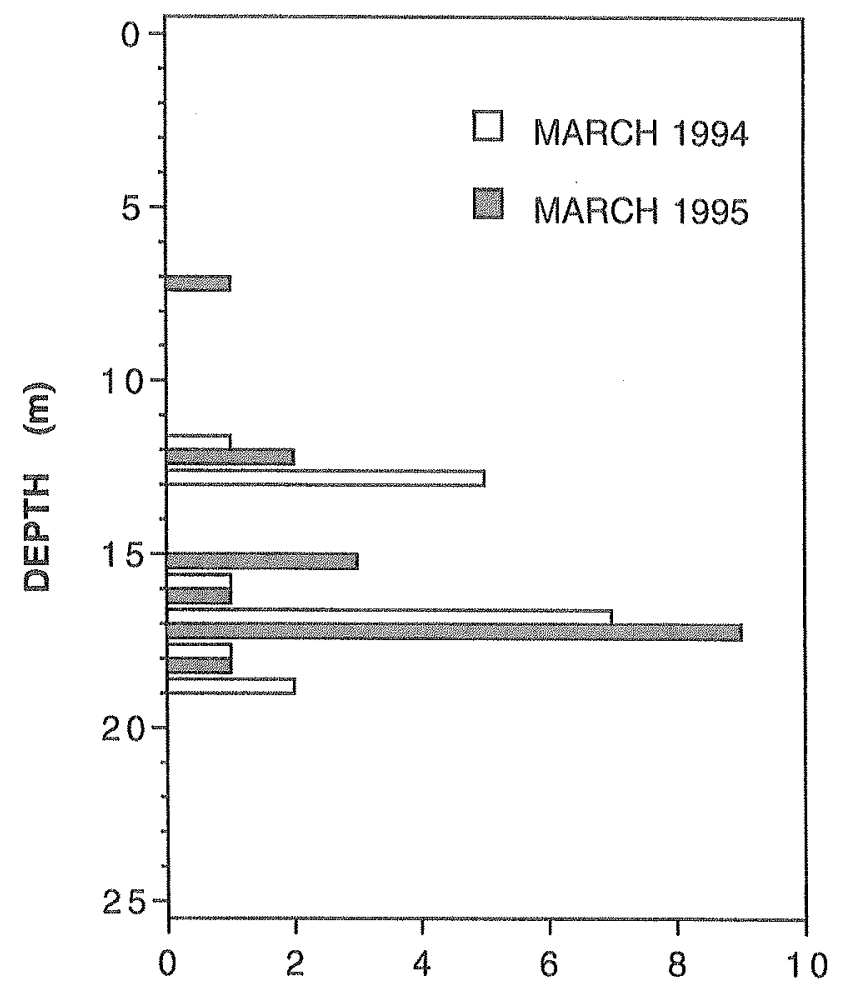

FREQUENCY

tic signal. Summer acoustic surveys using scientific echosounders equipped with time-varied gain, however, have found that much of the fish population in Redfish Lake was shallower than $30 \mathrm{~m}$ both day and night. In Alturas Lake, the salmon were shown to move from bottom and perimeter zones during the day to the limnetic zone (above $30 \mathrm{~m}$ ) at night (Teuscher and Taki 1995; Beauchamp et al. 1997). Since our stationary transducers were located in the deepest area of the lake, also near the middle of the lake, we did not sample nearshore areas where fish may have moved to feed 
Fig. 8. Theoretical O. nerka predation rate on zooplankton in (A and B) Stanley, (C) Redfish, and (D) Alturas lakes. Predation rate was calculated as a function of light intensity and zooplankton density (see text for complete details). Note the different bottom depths in each lake.
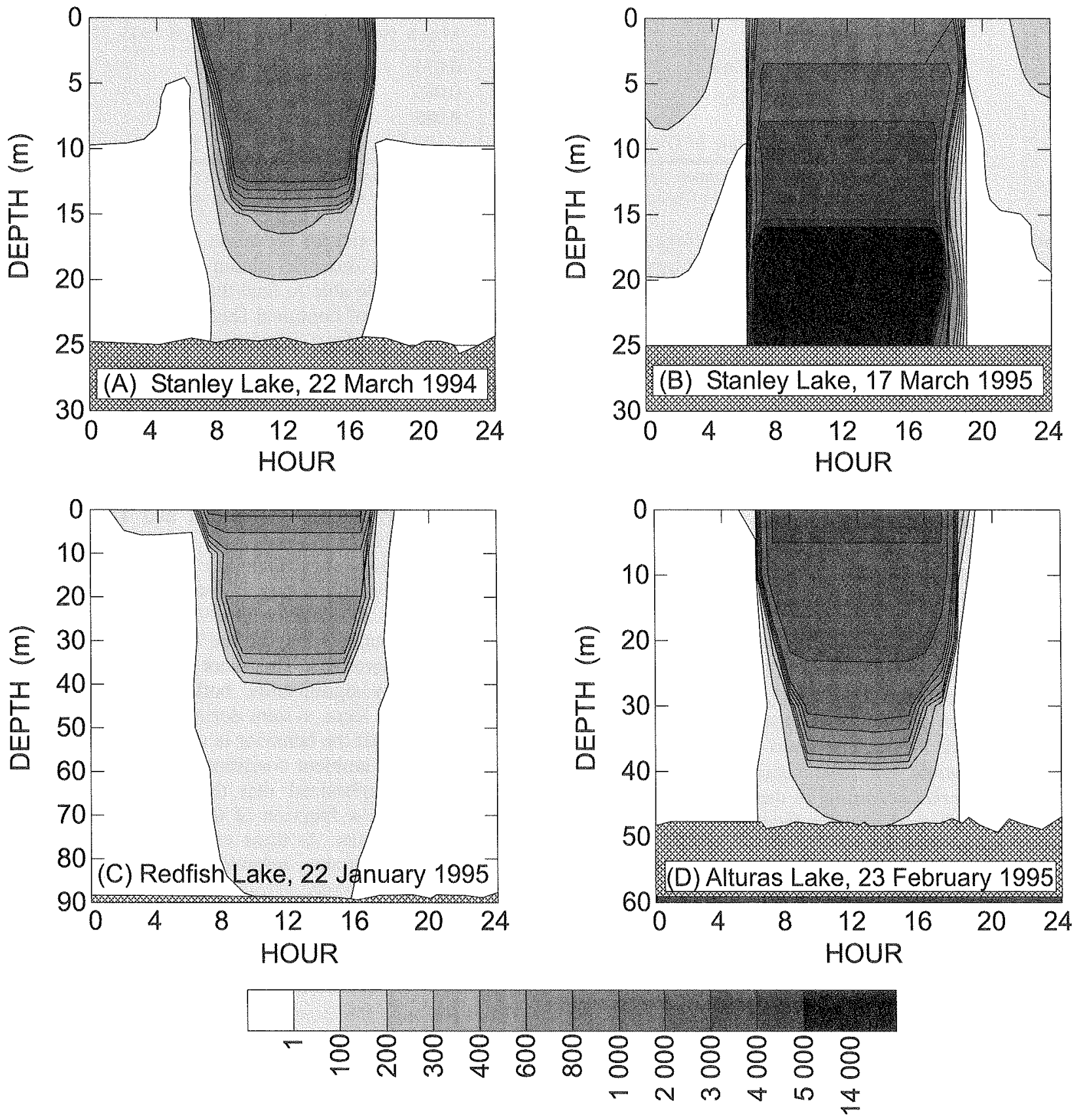

\section{O. NERKA PREDATION RATE (ZOOPLANKTON / h)}

or seek refuge. In addition, $O$. nerka on the bottom would not have been detected by our transducers. Therefore, we were not able to fully describe nearshore fish populations or detect some deep or benthically oriented fish. Future studies should address the possibility of a diel onshore-offshore migration, especially since it may be more prominent during the winter when food may be limiting salmon growth and survival.

The predator avoidance hypothesis may cause diel changes in salmon distribution in these lakes during summer (Beauchamp et al. 1997) and may explain some of the mi- gratory behavior seen in this study. Stanley Lake had the highest predation index (Table 2). As visual predators, lake trout also experience changes in foraging success based on light intensity. Data on lake trout foraging ability were not available, but Dolly Varden (Salvelinus malma), a closely related species, maintain maximum capture success to $0.6 \mathrm{~lx}$ and experience no capture success below $0.01 \mathrm{~lx}$ (Henderson and Northcote 1985). This suggests that lake trout foraging may be more light limited than $O$. nerka foraging; however, these data are for fish up to $30 \mathrm{~cm}$, and larger fish may have better vision (Ali 1959). During the day, high light intensi- 
Table 5. Foraging model predictions of consumption for different $O$. nerka migratory patterns in Stanley Lake.

\begin{tabular}{llc} 
& \multicolumn{2}{c}{ Consumption (\% dry weight/day) } \\
\cline { 2 - 3 } Pattern of migration & March 1994 & March 1995 \\
\hline No migration/remain shallow & 0.075 & 0.26 \\
No migration/remain deep & 0.085 & 1.19 \\
DVM & 0.095 & 1.25 \\
Increase in consumption due to DVM (\%) & 12 & 5 \\
\hline
\end{tabular}

Note: The increase in consumption was calculated from the difference between no migration/remain deep and the observed pattern of DVM (shallow at night, deep during the day). For details of the model, see text.

ties in Stanley Lake would not provide any refuge from lake trout predation. At night, however, $O$. nerka migrated to the surface where light levels permitted their feeding but may have reduced the reactive distance of lake trout, or even prohibited their feeding. Unless more accurate information on lake trout foraging is available, the predator avoidance hypothesis cannot be ruled out.

Predator avoidance likely did not play a role in structuring the observed fish distribution in Redfish and Alturas lakes. There was no vertical migration of salmon seen in Redfish Lake, which had the lowest predation index (Table 2). Although we have few data on predator behavior during winter in Redfish Lake, observations from Stanley and Alturas lakes suggest that even in winter, there is some risk of predation (Teuscher and Taki 1995). In Alturas Lake, there was a slight downward migration of $O$. nerka during the day, and gillnetting indicated that bull trout were at least occasionally in the pelagic zone (G.B. Steinhart, unpublished data). Consequently, bull trout present a predation risk for O. nerka, as do northern squawfish (Kline 1994; Teuscher and Taki 1995). The short migration in Alturas Lake, however, would not have significantly reduced fish predation on $O$. nerka; according to the light data, intensities would still have allowed visually feeding bull trout to prey on them. Predator avoidance may have contributed to the DVM in Stanley Lake, but the lack of significant migrations in Alturas and Redfish lakes suggests that predation risk does not always influence fish migrations.

In winter, temperature was not likely a factor influencing vertical migrations of $O$. nerka. Only a small temperature gradient existed under the ice and should not have significantly affected growth. Bioenergetics simulations showed that juvenile $O$. nerka growth at $2.7^{\circ} \mathrm{C}$ is only $2 \%$ less than growth experienced at $4^{\circ} \mathrm{C}$ (G.B. Steinhart, unpublished data). During winter, it is reasonable to assume that changes in temperature are not a factor in determining the patterns of DVM of $O$. nerka in these lakes.

Given these results, it appears that feeding ability (a combination of foraging success and zooplankton density) best describes the patterns of $O$. nerka DVM in two of the three lakes during winter. Specifically, low light penetration through accumulated snow and ice limited foraging success of visually feeding salmon. Predator avoidance may stimulate salmon migrations in some other systems (Levy 1987, 1990b; Clark and Levy 1988; Bevelhimer and Adams 1993), but we did not see any vertical migrations to avoid predators in either Redfish Lake or Alturas Lake, but the cause of DVM in Stanley Lake is still undetermined. Low zooplankton densities and light-limited foraging success may have outweighed the risk of predation during these surveys. We suggest that in order to obtain adequate food in winter, $O$. nerka must be able to feed throughout the day and night. The advantages of continual feeding may outweigh the possible risks of predator avoidance in these systems. In summer, when zooplankton are more abundant, temperature effects and (or) predator density may alter these observed migration patterns. In fact, during summer, O. nerka in Redfish and Alturas lakes were typically found near the bottom during the day and in the metalimnion at night, while $O$. nerka in Stanley Lake stayed in shallow water to avoid the anoxic hypolimnion (Teuscher and Taki 1994; Beauchamp et al. 1997).

This study does not dispute any of the current hypotheses on $O$. nerka DVM; however, it does demonstrate that during periods of low zooplankton densities and low light intensities, foraging success may be the dominant factor in sculpting vertical migrations. This work also shows that $O$. nerka migrations vary significantly, both in similar systems and even within the same system during different times of year. This suggests that the behavior is very plastic and changes in response to the ambient conditions. Bevelhimer and Adams (1993) also emphasized that there is no set pattern for DVMs: they are a function of temperature, feeding ability, and predator density. As these variables change among lakes or seasons, the migratory behavior of fishes will also change.

\section{Acknowledgments}

Funding for this project came from the Ecology Center, Utah State University, and the Shoshonne-Bannock Indian Tribes (through the Bonneville Power Administration); however, the findings and conclusions presented by the authors are their own. We would also like to acknowledge all those people who helped collect the data necessary for this project: Odette Brandt, Phaedra Budy, Michelle Gregg, Howard Gross, Chad Mellison, Fredrick Norrsell, Rick Orme, John Ossowski, Mike Slater, and Darek Staab were all generous enough to help during rough field conditions. A special thank you goes to Doug Taki, David Teuscher, and Paul Kline for help in the field and sharing of data. We would also like to thank David Beauchamp, Dana Vaughan, Doran Mason, and two anonymous reviewers for comments on earlier drafts of this manuscript.

\section{Reterences}

Ali, M.A. 1959. The ocular structure, retinomotor and photo-behavioral responses of juvenile pacific salmon. Can. J. Zool. 37; 965-998. 
Beauchamp, D.A., Luecke, C., Wurtsbaugh, W.A., Gross, H.G., Budy, P., Spaulding, S., Dillenger, R., and Gubala, C.P. 1997. Hydroacoustic assessment of abundance and diel distribution of sockeye salmon and kokanee in the Sawtooth Valley lakes, Idaho. N. Am. J. Fish. Manage. 17: 253-267.

Bevelhimer, M.S., and Adams, S.M. 1993. A bioenergetics analysis of diel vertical migration by kokanee salmon, Oncorhynchus nerka. Can. J. Fish. Aquat. Sci. 50: 2336-2349.

Brett, J.R. 1971. Energetic responses of salmon to temperature. A study of some thermal relations in the physiology and freshwater ecology of sockeye salmon (Oncorhynchus nerka). Am. Zool. 11: 99-113.

Brett, J.R. 1983. Life energetics of sockeye salmon, Oncorhynchus nerka. In Behavioral energetics: the cost of survival in vertebrates. Edited by W.P. Aspey and I. Lustic. Ohio State University Press, Columbus, Ohio. pp. 29-63.

Brett, J.R., and Groves, T.D.D. 1979. Physiological energetics. In Fish physiology. Vol. 8. Edited by W.S. Hoar, D.J. Randall, and J.R. Brett. Academic Press, New York. pp 279-352.

Budy, P., Luecke, C., Wurtsbaugh, W.A., Gross, H.P., and Gubala, C. 1995. Limnology of the Sawtooth Valley lakes with respect to potential growth of juvenile Snake River sockeye salmon. Northwest Sci. 69: 133-150.

Clark, A.N.W., and Levy, D.A. 1988. Diel vertical migrations by juvenile sockeye salmon and the antipredation window. Am. Nat. 131: 271-290.

Cunningham, L. 1972. Vertical migrations of Daphnia and copepods under the ice. Limnol. Oceanogr. 17: 301-303.

Dodson, S.I. 1975. Predation rates of zooplankton in arctic ponds. Limnol. Oceanogr. 20: 426-433.

Eggers, D.M. 1978. Limnetic feeding behavior of juvenile sockeye salmon in Lake Washington and predator avoidance. Limnol. Oceanogr. 23: 1114-1125.

Henderson, M.A., and Northcote, T.G. 1985. Visual prey detection and foraging in sympatric cutthroat trout (Salmo clarki clarki) and dolly varden (Salvelinus malma). Can. J. Fish. Aquat. Sci. 42: 785-790.

Janiczek, P.M., and Young, A.J. 1987. Computer program for sun and moon illuminance with contingent tables and diagram. Circ. U.S. Nav. Observatory No. 171

Johnston, N.T. 1990. A comparison of the growth of verticallymigrating and non migrating kokanee (Oncorhynchus nerka) fry. Can. J. Fish. Aquat. Sci. 47: 486-491.

Kline, P. 1994. Research and recovery of Snake River sockeye salmon. Annu. Rep. 1993. Project No. 91-72. U.S. Department of Energy, Bonneville Power Administration, Portland, Oreg.

Koenings, J.P., Edmundson, J.E., Kyle, G.B., and Edmundson, J.M. 1987. Limnological field and laboratory manual: methods for assessing aquatic production. Alaska Dep. Fish Game FRED Div. Rep. Ser. No. 71.
Lampert, W. 1989. The adaptive significance of diel vertical migration of zooplankton. Funct. Ecol. 3: 21-27.

Levy, D.A. 1987. Review of the ecological significance of diel vertical migrations by juvenile sockeye salmon (Oncorhynchus nerka). In Sockeye salmon (Oncorhynchus nerka) population biology and future management. Edited by H.D. Smith, L. Margolis, and C.C. Wood. Can. Spec. Publ. Fish. Aquat. Sci. No. 96. pp. 44-52.

Levy, D.A. 1990 a. Reciprocal diel vertical migration behavior in planktivores and zooplankton in British Columbia lakes. Can. J. Fish. Aquat. Sci. 47: 1755-1764.

Levy, D.A. 1990b. Sensory mechanism and selective advantage for diel vertical migration in juvenile sockeye salmon, Oncorhynchus nerka. Can. J. Fish. Aquat. Sci. 47: 1796-1802.

Levy, D.A. 1991. Acoustic analysis of diel vertical migration behavior of Mysis relicta and kokanee (Oncorhynchus nerka) within Okanagan Lake, British Columbia. Can. J. Fish. Aquat. Sci. 48: 67-72.

McCauley, E. 1984. The estimation of the abundance and biomass of zooplankton in samples. In A manual on methods of secondary productivity in freshwaters. 2nd ed. Edited by J.A. Downing and F. Rigler. Blackwell Scientific Publications, Cambridge, Mass. pp. 228-265.

Narver, D.W. 1970. Diel vertical movements and feeding of underyearling sockeye salmon and the limnetic zooplankton in Babine Lake, British Columbia. J. Fish. Res. Board Can. 27: 281-316.

Neverman, D., and Wurtsbaugh, W.A. 1994. The thermoregulatory function of diel vertical migration for a juvenile fish, Cottus extensus. Oecologia, 98: 247-256.

Sokal, R.R., and Rohlf, F.J. 1981. Biometry. W.H. Freeman and Company, New York.

Spaulding, S. 1993. Snake River sockeye salmon (Oncorhynchus nerka) habitat/limnology research. Annu. Rep. 1992. DOE/BP 22548-1. U.S. Department of Energy, Bonneville Power Administration, Portland, Oreg.

Steinhart, G.B. 1997. Winter limnology and the ecology of Oncorhynchus nerka in high-mountain lakes of Idaho. Master's thesis, Utah State University, Logan, Utah.

Teuscher, D.M., and Taki, D. 1994. Snake River sockeye salmon habitat and limnological research. Annu. Rep. 1993. DOE/BP 22548-2. U.S. Department of Energy, Bonneville Power Administration, Portland, Oreg.

Teuscher, D., and Taki, D. 1995. Snake River sockeye salmon habitat and limnological research. Annu. Rep 1994. DOE/BP 22548-3. U.S. Department of Energy, Bonneville Power Administration, Portland, Oreg.

Wetzel, R.G., and Likens, G.E. 1991. Limnological analyses. SpringerVerlag, New York.

Wurtsbaugh, W.A., and Neverman, D. 1988. Post-feeding thermotaxis and daily vertical migration in a larval fish. Nature (Lond.), 33: 846-848. 